\title{
CADMIUM REMOVAL BY USING PUMICE MODIFIED WITH IRON NANOPARTICLES FROM AQUEOUS SOLUTIONS
}

\author{
SHOKOOHI R. ${ }^{1}$ \\ ZOLGHADRNASAB H. ${ }^{2}$ \\ AZARIAN G. ${ }^{1, *}$ \\ MEHDIPOUR M. ${ }^{2}$
}

\author{
${ }^{1}$ Department of Environmental Health Engineering \\ Faculty of Health and Research Center for Health Sciences \\ Hamadan University of Medical Sciences, Hamadan, Iran \\ ${ }^{2}$ Department of Environmental Health Engineering \\ Hamadan University of Medical Sciences, Hamadan, Iran
}

*to whom all correspondence should be addressed:
e-mail: gh_azarian@yahoo.com

$*_{\text {to }}$ whom all correspondence should be addressed:
e-mail: gh_azarian@yahoo.com
Received: 03/12/2015

Accepted: $18 / 04 / 2016$

Available online: $11 / 05 / 2016$

\section{ABSTRACT}

In this study, the removal of cadmium by using pumice coated with iron nanoparticles (INPs) from synthetic wastewater was investigated. The effects of parameters influencing adsorption: contact time (10-20 min), $\mathrm{pH}$ (3-9), initial cadmium concentration (25-125 $\left.\mathrm{mg} \mathrm{l}^{-1}\right)$ and adsorbent dose $\left(2-10 \mathrm{~g}^{-1}\right)$ were studied. The pumice stone used in this research was, first, crashed and then sieved with 20 mesh standard sieves $(0.85 \mathrm{~mm})$; finally, it was coated with INPs. An atomic absorption spectrophotometer was used to measure cadmium contents and isotherm models and adsorption kinetics were studied. The results showed the adsorption process of cadmium reached equilibrium at contact time of $80 \mathrm{~min}$. With increasing $\mathrm{pH}$ solution, the efficiency enhanced which peaked at $\mathrm{pH}$ 7-8. Cadmium concentration increase resulted in a decrease in efficiency, whereas adsorbent dose increase improved it. Equilibrium data of adsorption followed isotherms models: Langmuir and Freundlich. The highest removal efficiency and adsorption capacity were, respectively, $83 \%$ and $17.27 \mathrm{mg} \mathrm{g}^{-1}$. Furthermore, absorption kinetics is better described by the pseudo second-order model. According to the results obtained, pumice coated with INPS is an effective adsorbent and can be introduced as a suitable option in practical applications.

Keywords: Wastewater, Cadmium, Adsorption, Pumice-Modified Iron Nanoparticles

\section{Introduction}

In recent years, discharge of wastewaters containing heavy metals ions to the environment has been one of main challenges of industrial and semi-industrial countries. Heavy metals are persistent and unbiodegradable in environment and can be accumulated in aquatic organisms (Turan et al., 2011). Cadmium is used as a raw material in processes such as metallurgy, cadmium - nickel batteries production, oil dyes, mining, stabilizers and alloys. Cadmium, even at low contents, is harmful to human, which can create various problems as follows: cancer, hyperglycemia, immune deficiency and anemia. Thus, this metal is considered as priority pollutants in many countries (Regmi et al., 2012; Pérez-Marín et al., 2007).

Several physical and chemical methods: precipitation, membrane filtration, ion exchange, activated carbon adsorption and precipitation/adsorption has been extensively applied to remove cadmium from industrial effluents (Turan et al., 2011; Regmi et al., 2012; Pérez-Marín et al., 2007), which of these processes have their both advantages and disadvantages. Adsorption is considered as an effective and economical method for wastewater treatment because of its easy operation and high efficiency. Various adsorbents such as activated carbon, zeolites, mineral clays, lignocelluloses, natural minerals, modified 
polymers, etc. have been taken into account for removing pollutants from aqueous environments. Nonetheless, these adsorbents have some drawbacks like diffusion limitation, lack of active surface sites, high price and difficult separation from wastewater and by-products generation. Nanoadsorbents such as nano-alumina, modified carbon nanotubes, zero-valent iron nanoparticles (INPs) which have higher efficiency have been recently employed (Turan et al., 2011; Gupta and Nayak, 2012; Boparai et al., 2011).

INPs because of lower adsorbent demand, lower sludge production, easier recovery property of adsorbed pollutants and lower costs have been more considered for pollutant removal (Laurent et al., 2008; Wang et al., 2010). INPs (extremely small particle) have extensive surface and high activity and can be taken into account as one of the most hopeful and effective technologies in removing heavy metals from aqueous media (Shi et al., 2011). The practical application of INPs is limited because of density and accumulation of these nanoparticles in conventional systems and, in turn, a decrease in their activity and mechanical power. Thus, in order to raise the dispersion property of INPs, porous materials such as zeolites, kaolinite, bentonite and clay have been widely used as mechanical keeper (Shi et al., 2011; Li et al., 2007; Üzüm et al., 2009). Recently, many researchers have utilized chitosan beds to increase dispersion and stability of Zero-valent INPs in air and wastewater. However, these beds are needed to be improved (Geng et al., 2009; Liu et al., 2010; Liu et al., 2012; Chandy and Sharma, 1993). Moreover, these are expensive. Pumice is an inexpensive stone, which is found abundantly in Iran; it has the following characteristics: lightness, high porosity (pore volume over $80 \%$ ). Moreover, this stone can be either acidic or basic. All of this has resulted in high application in water and wastewater works as from a keeper of filter beds, and catalyst to an adsorbent in removing pollutant from water solutions (Yavuz et al., 2008; Catalfamo et al., 2006). Furthermore, it is easily processed and can be used as a cheap adsorbent for the adsorption of heavy metals. Granular pumice is covered in metallic salts having high performance and long hydraulic activity in removing various pollutants (Moraci and Calabrò, 2010). Liu et al., studied heavy metals (mercury and hexavalent chromium) removal by means of zero-valent INPs and in a similar study by Moraci et al., nickel and copper were removed (Moraci and Calabrò, 2010; Liu et al., 2014). Rahmani and co-workers used commercial iron to remove hexavalent chromium (Rahmani, 1898). To our best knowledge, no study has not applied pumice as a keeper of INPs for removing cadmium before. Since there are a huge number of pumice mines around the country Iran, particularly in Ghorveh, Kurdistan Province, this research was aimed to investigate the performance of pumice modified by INPs for cadmium removal from aqueous environments.

In the current study, pumice coated with INPs was used to remove cadmium from synthetic wastewater. Besides, the effects of operating parameters- contact time, $\mathrm{pH}$, cadmium initial concentration, and adsorbent dose were studied. Of course, adsorption isotherms and reaction kinetics of cadmium adsorption on the pumice coated by INPs were measured.

\section{Materials and Methods}

\subsection{Chemicals and apparatuses}

All chemicals, $\mathrm{Cd}\left(\mathrm{NO}_{3}\right), \mathrm{NH}_{3} \mathrm{H}_{2} \mathrm{O}, \mathrm{HCl}, \mathrm{H}_{2} \mathrm{SO}_{4}, \mathrm{NaOH}, \mathrm{FeCl}_{3}$, and $\mathrm{FeCl}_{2}$ used were of analytical laboratory grade and purchased from Merck Co., Germany. All samples were prepared synthetically in this study. The stock solution was prepared by dissolving accurately $1.372 \mathrm{~g}$ of $\mathrm{Cd}\left(\mathrm{NO}_{3}\right)$ in de-ionized water and other concentrations were made from this solution. $\mathrm{H}_{2} \mathrm{SO}_{4}$ and $\mathrm{NaOH}(0.1 \mathrm{~N})$ were used to adjust $\mathrm{pH}$ by means of a digital pH-meter (model 4 Sension $\mathrm{HACH}$, Germany). All samples were mixed by a shaking incubator (Pars azma, Iran) and adsorbent separation was performed by a centrifuge (Sigma 301, Germany). Cadmium contents were measured by using atomic absorption spectrophotometer equipped with electrothermal an atomization unit (Thermo Jarrell Ash, USA) at wavelength of $226.8 \mathrm{~nm}$. A scanning electronic microscope (Philips XL-30: SEM) and FTIR spectrometer (Perkin-Elmer Inc., Norwalk, CT, USA) were used to investigate the morphology of the surface of the adsorbent. 


\subsection{Adsorbent Preparation and adsorption experiments}

The pumice stone was taken from a region in Ghorveh City of Kurdistan Province, Iran. To the best of our knowledge, the best way of preparation of pumice and its coating with INPs was selected and conducted. First of all, it was kept in $\mathrm{HCl}(0.1 \mathrm{~N})$ for $30 \mathrm{~h}$ for removing pollutants and impurities from its surface. Next, it was washed thoroughly with distilled water. After drying pumice in autoclave for $24 \mathrm{~h}$ (at $120^{\circ} \mathrm{C}$ ), it was crashed and then sieved with 20 mesh standard sieves $(0.85 \mathrm{~mm})$ ASTM. After washing successively with distilled water, it was dried at $40{ }^{\circ} \mathrm{C}$ for $72 \mathrm{~h} .173 \mathrm{~g}$ of $\mathrm{FeCl}_{3}$ and $63 \mathrm{~g}$ of $\mathrm{FeCl}_{2}$ were mixed at high speed for $5 \mathrm{~min}$ and $0.8 \mathrm{~L}$ of pumice and $60 \mathrm{ml}$ of $\mathrm{NH}_{3} \mathrm{H}_{2} \mathrm{O}$ was added to it and then was kept at $105^{\circ} \mathrm{C}$ for $24 \mathrm{~h}$. Next, it was heated at $300{ }^{\circ} \mathrm{C}$ for $1.5 \mathrm{~h}$. After washing, the obtained adsorbent was kept out of light in polyethylene containers for later uses (Lee et al., 2012).

The effects of parameters influencing adsorption including contact time $(10,20,30,40,60,80,100$ and $120 \mathrm{~min}), \mathrm{pH}$ (3-9), cadmium initial concentration (25, 50, 75, 100 and $125 \mathrm{mg} \mathrm{l}^{-1}$ ) and adsorbent dose (2, 4, 6, 8 and $10 \mathrm{~g} \mathrm{l}^{-1}$ ) were investigated. In order to obtain optimum conditions, the variables were varied as one at a time (Rahmani et al., 2015). After adjusting desire circumstances, the samples were kept in a shaker incubator $(150 \mathrm{rpm})$ at $25^{\circ} \mathrm{C}$. Then, the samples were centrifuged $(400 \mathrm{rpm})$. The concentrations of residual cadmium were detected. In order to increasing confidence coefficient and accuracy of the results, all experiments were repeated three times and the averages of them were reported. The amounts of removal efficiency of cadmium and the adsorption capacity of the adsorbent were calculated, respectively, by the equations as follows (Boparai et al., 2011):

$$
\begin{aligned}
& R(\%)=\frac{C_{i}-C_{e}}{C_{i}} \times 100 \\
& q_{e}=\frac{\left(C_{i}-C_{e}\right) V}{M}
\end{aligned}
$$

Where $R(\%)$ presents removal efficiency of cadmium, $\mathrm{q}_{\mathrm{e}}$ is the amount adsorbed $\left(\mathrm{mg} \mathrm{g}^{-1}\right), \mathrm{C}_{\mathrm{i}}$ and $\mathrm{C}_{\mathrm{e}}$ are, respectively, initial and final concentrations of cadmium per unit $\left(\mathrm{mg} \mathrm{l}^{-1}\right), \mathrm{V}$ is the volume of the wastewater in reactor (I) and $\mathrm{M}$ is the mass of the adsorbent (g).

\subsection{Reaction kinetic and adsorption isotherm}

In order to detect kinetic reaction, a solution with initial content of $50 \mathrm{mg} \mathrm{l}^{-1}$ of cadmium at $\mathrm{pH}=8$ and adsorbent dose $=8 \mathrm{~g} \mathrm{l}^{-1}$ was prepared. From the prepared solution, samples were taken at time intervals between 10 and $120 \mathrm{~min}$ and then the residual concentration of cadmium was measured after adsorbent separation; next, the gained data were used to calculate kinetic reaction. Reaction kinetics shows the rate of chemical reactions. In this study, adsorption rate constant through pumice coated with INPs was followed by kinetic models of pseudo first-order and pseudo second-order and the most suitable model were selected. Equations 3 and 4 show the first-order and pseudo-second order kinetics (Boparai et al., 2011).

$$
\begin{aligned}
& \ln \left(q_{e}-q_{t}\right)=\ln q_{e}-k_{t} t \\
& \frac{t}{q_{t}}=\frac{1}{k_{2} q_{e}^{2}}+\frac{t}{q_{e}}
\end{aligned}
$$

Where $q_{e}$ is the equilibrium concentration of the adsorbent $\left(\mathrm{mg} \mathrm{g}^{-1}\right), q_{t}$ is the concentration of cadmium at time $t\left(\mathrm{mg} \mathrm{g}^{-1}\right)$ and $K_{t}$ and $K_{2}$ are rate constants of pseudo first-order and pseudo second-order equations.

In order to study adsorption isotherms, solutions having the following conditions: initial cadmium concentrations $=25,50,75,100,125 \mathrm{mg} \mathrm{l}^{-1}, \mathrm{pH}=8$, and adsorbent dose $=8 \mathrm{~g} \mathrm{l}^{-1}$ were made and were kept in a shaker incubator for $80 \mathrm{~min}$, which was the equilibrium time of past stage. Next, the residual 
concentrations of cadmium were detected the equilibrium data were fitted to the Langmuir and Freundlich isotherms (equations: 5 and 6) (Coruh et al., 2014; Luo et al., 2013; Salman et al., 2016).

$$
\begin{aligned}
& \frac{C_{e}}{q_{e}}=\frac{1}{q_{\max } b}+\frac{C_{e}}{q_{\max }} \\
& \operatorname{lnq}_{e}=\operatorname{lnk} k_{f}+\frac{1}{n} \ln C_{e}
\end{aligned}
$$

Where $\mathrm{q}_{\max }$ presents adsorption capacity $\left(\mathrm{mg} \mathrm{g}^{-1}\right), b$ is Langmuir constant- which is related to adsorption temperature $(\mathrm{J} / \mathrm{mol})$ and calculated by drawing diagram of $\frac{\mathrm{C}_{e}}{\mathrm{q}_{e}}$ against $\mathrm{C}_{e}$, and $\mathrm{K}_{\mathrm{f}}$ and $\mathrm{n}$ are Freundlich constants. In Langmuir model, $R_{\mathrm{L}}$, by which the kind of the process is determined, is a dimensionless parameter and is calculated as the following equation (Luo et al., 2013):

$$
\mathrm{R}_{\mathrm{L}}=\frac{1}{(1+\mathrm{bC})}
$$

If $R_{L}>1$, the adsorption is unfavorable, $R_{L}=1$, the adsorption is linear, $R_{L}<1$, the adsorption is favorable and $R_{L}=0$, the adsorption is irreversible.

The applicability and fitting of the isotherm equation to the kinetic data was compared by evaluating from the $R^{2}$ values and the normalized standard deviation $\Delta q(\%)$ calculated from equation 8 . The normalized standard deviation confirms kinetic model used in the adsorption process.

$$
\Delta q(\%)=100 \times \frac{\sqrt{\sum\left(\frac{q_{e} \exp -q_{e} c a l}{q_{e} \exp }\right)^{2}}}{(n-1)}
$$

where $\mathrm{q}_{\mathrm{e}} \exp$ and $\mathrm{q}_{\mathrm{e}} \mathrm{cal}\left(\mathrm{mg} \mathrm{g}^{-1}\right)$ are the experimental and calculated adsorption capacity values, respectively and $n$ is the number of data points. Lower value of $\Delta q(\%)$ shows good fit between experimental and calculated data.

\section{Results and discussion}

According to Fig. 1, the results from cadmium removal by means of pumice with or without INPs coating illustrated that pumice without coating could not able to treat the pollutant well (in fixed conditions listed in the Fig. 1), as the process reached a $42 \%$ removal efficiency in $80 \mathrm{~min}$.

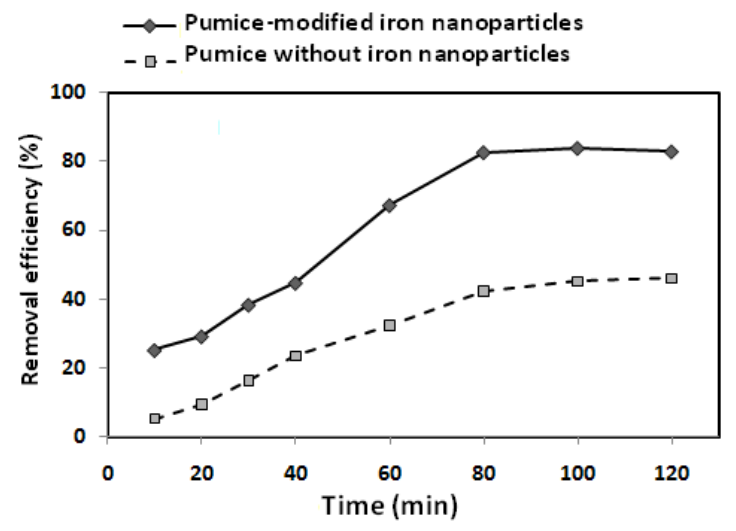

Figure 1. Removal of cadmium by using pumice without iron nanoparticles and pumice coated with iron nanoparticles: (initial cadmium concentration: $50 \mathrm{mg} \mathrm{l}^{-1}$, adsorbent dose: $8 \mathrm{~g} \mathrm{I}^{-1}$ and $\mathrm{pH}$ 7) 
In contrast, pumice coated with INPs could remove $83 \%$ of cadmium in the same time. Thus, pumice coated with INPs was applied to study adsorption isotherms and optimize the variables.

\subsection{The effect of operating parameter}

The SEM images of the natural and modified with INPs pumice stone have been shown in Fig. 2 .
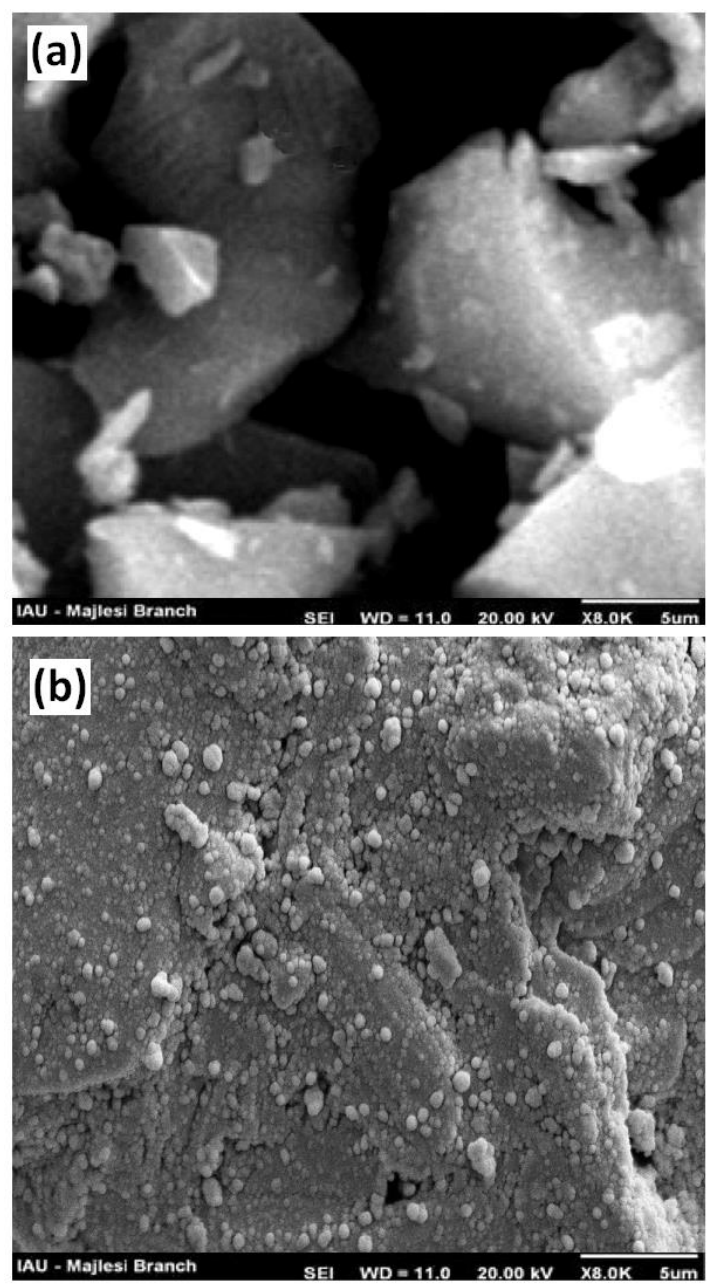

Figure 2. Scanning electronic microscope (SEM) image: (a) natural pumice stone and (b) pumice stone coated with iron nanoparticles

As can be seen, the surface of the modified pumice has well been coated with INPs. Fig. 3, presents FTIR spectra of the natural and modified with INPs pumice stone. After modification the bands of Fe-O band around 544 and $468 \mathrm{~cm}^{-1}$ were observed, which supported the presence of INPs. Fig. 4, shows the effects of operating parameters on cadmium removal and the adsorption capacity of the adsorbent. The results of $\mathrm{pH}$ effect is indicative of the fact that the efficiency increased by increasing $\mathrm{pH}$ value, as the least and highest efficiencies were $19.6 \%$ and $83.38 \%$, respectively, at pHs of 3 and 8 ; simultaneously, there was an increase in adsorption capacity which reached to $6.63 \mathrm{mg} \mathrm{g}^{-1}$ from $1.63 \mathrm{mg} \mathrm{g}^{-1}$ (Fig. 4a). The pH of solution is one the most important variables influencing adsorption of metal ions through effect on electric charge of adsorbent surface, ionization degree and ionic species of the adsorbent (Regmi et al., 2012). At pHs over $7, \mathrm{Cd}(\mathrm{OH})^{+}$and $\mathrm{Cd}(\mathrm{OH})_{2}$ are the predominant forms of cadmium existing in solution; thus, main species in solution can be shown as follows:

$$
\mathrm{Cd}^{2+}+\mathrm{OH}^{-} \rightarrow \mathrm{Cd}(\mathrm{OH})^{+}
$$




$$
\mathrm{Cd}(\mathrm{OH})^{+}+\mathrm{OH}^{-} \rightarrow \mathrm{Cd}(\mathrm{OH})_{2}
$$

In addition, at pH more than 7 there is a slight possibility of the presence of metallic hydroxides in the pores or space of around particles and the amount of cadmium removal via precipitation is higher than adsorption. Therefore, precipitation plays an important role in heavy metals removal at alkaline conditions. At $\mathrm{pH}$ of 3 , adsorption works weekly owing to intense competition between high concentrations of $\mathrm{H}^{+}$and $\mathrm{H}_{3} \mathrm{O}^{+}$. However, the capacity of adsorption goes up sharply at $\mathrm{pH}$ of 5 which can be attributed to surface tension increase of the adsorbent towards cadmium ions. With increasing $\mathrm{pH}$, the competition of protons and metallic species for adsorption sites as well as positive charge is lowered, leading to increase in adsorption. At pH 7, hydrolyze of cadmium ions is more than acidic $\mathrm{pH}$ and higher capacity of adsorption may be owing to adsorptions mechanisms and precipitation (Luo et al., 2013). The results of similar studies support the results of this stage. Luo et al. reported that the highest efficiency of cadmium removal by means of multiwalled carbon nanotubes modified with dioxide magnesium occurred at pH 7 (Luo et al., 2013). Gupta and Nayak, found that the adsorption capacity of cadmium on orange peel powder, INPs and orange peel powder modified with INPs had an upward trend in the range of pH between 2 and 7 and then decreased with increasing $\mathrm{pH}$ value (Gupta and Nayak, 2012). In a similar study by Liu et al., in which the removal efficiency of heavy metals of mercury by means of pumice coated with zero-valent INPs was investigated, it was found that the efficiency increased with increasing pH from 3.11 to 7.13 (Liu et al., 2014).
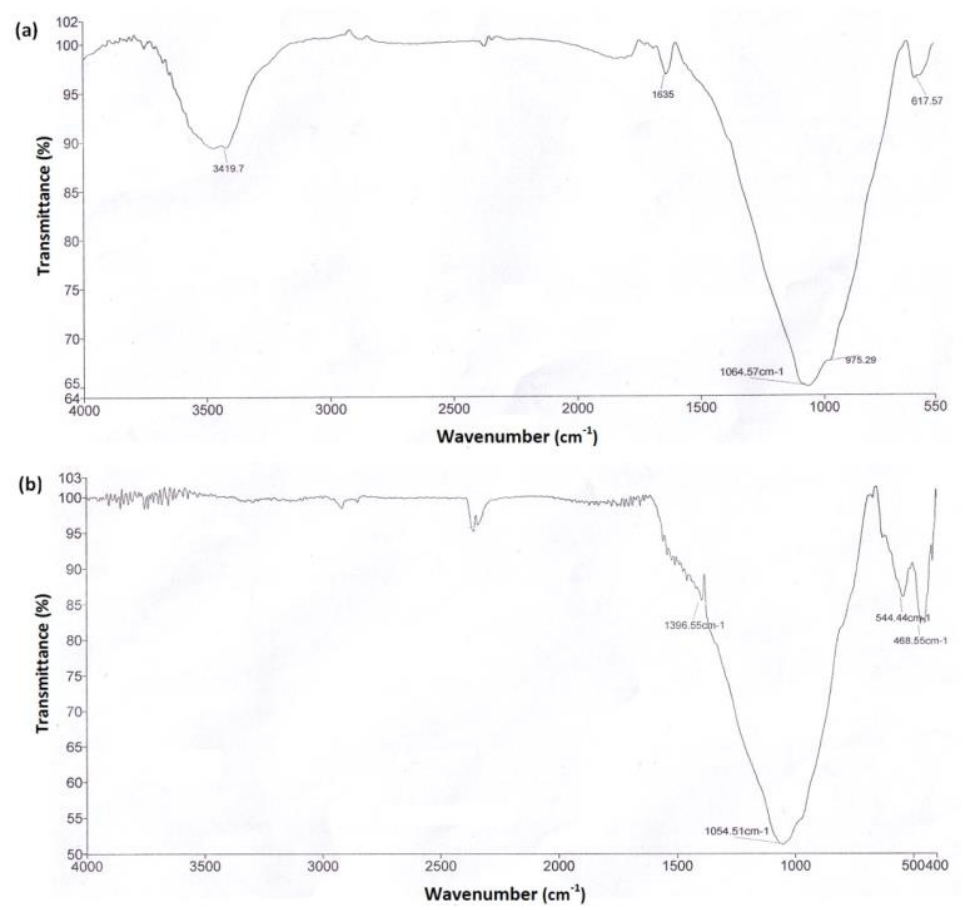

Figure 3. FTIR spectra of (a) natural pumice stone and (b) pumice stone coated with iron nanoparticles

According to Fig. $4 \mathrm{~b}$, with increasing initial cadmium concentration resulted in a decrease in efficiency, as with increasing concentration from 25 to $125 \mathrm{mg} \mathrm{l}^{-1}$ the removal efficiency decreased from $68.8 \%$ to $51.8 \%$. Simultaneously, the adsorption capacity of cadmium increased from 2.86 to $10.79 \mathrm{mg} \mathrm{g}^{-1}$. The highest efficiency of cadmium removal was gained at concentration of $50 \mathrm{mg} \mathrm{l}^{-1}$ which the adsorption capacity of cadmium was approximately $6 \mathrm{mg} \mathrm{g}^{-1}$. With increasing initial concentration of heavy metals, with fixed dose of adsorbent, the adsorption sites are limited and the amount of heavy metal removal decreases (Liu et al., 2014). At low contents of pollutants, there are more active sites than the number of adsorbate species; thus, the efficiency goes up at low concentrations of adsorbate matter (Lee et al., 2012). Simultaneously, with increasing initial cadmium concentration the adsorption capacity also increases 
which is because of thrust force of cadmium ions in solution towards the adsorbent and more contacts of the ions with adsorption sites (Gupta and Nayak, 2012). Our results accorded with those of recent studies, in which copper, cadmium and lead were adsorbed on Enhanced chitosan $/ \mathrm{Fe}^{0}$-nanoparticles beads (Liu et al., 2012; Lee et al., 2012). Also, in study by Liu et al., there was a downward trend in removal efficiency of chromium and mercury through pumice coated with zero-valent INPs (Liu et al. 2014).

The findings showed that with increasing adsorbent dose from 2 to $10 \mathrm{gl}^{-1}$ the efficiency rose by $53 \%$ and the adsorption capacity decreased by $3.31 \mathrm{mg} \mathrm{g}^{-1}$ (Fig. 4c). In view of the fact that with increasing adsorbent dose over $8 \mathrm{~g} \mathrm{l}^{-1}$ a significant change was not observed in efficiency, thus, the dose of $8 \mathrm{~g} \mathrm{l}^{-1}$ with adsorption capacity of $5.08 \mathrm{mg} \mathrm{g}^{-1}$ was selected as the optimum point. Dose increase results in an increase in surface area and active sites (Liu et al., 2015). More adsorbent dose increases adsorption sites, which causes time reaction to reach equilibrium sooner. When adsorbent dose increases, active sites on adsorbent surface are not saturated and, in turn, adsorption capacity decreases (Phuengprasop et al., 2011).
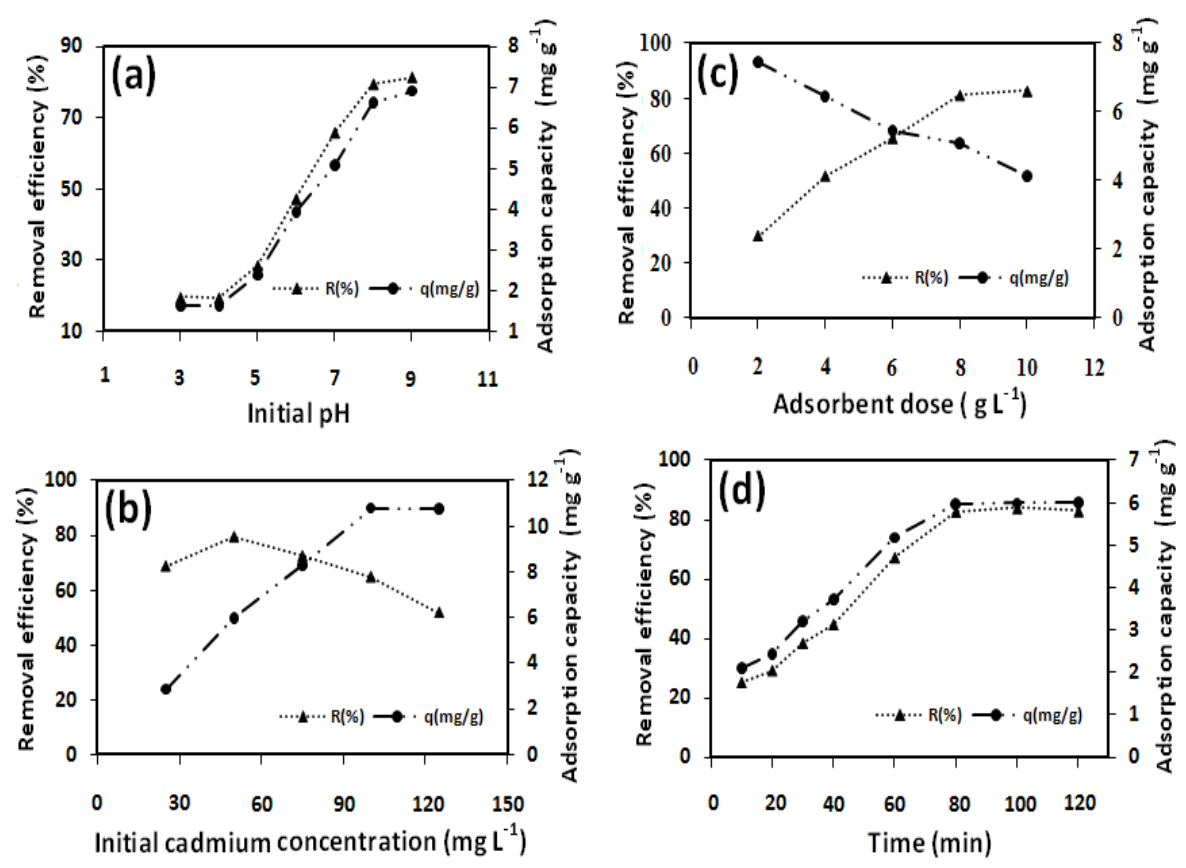

Fig 4: Effect of operating parameters (a) pH, (b) initial cadmium concentration, (c) adsorbent dose, (d) contact time on cadmium removal and adsorption capacity (initial cadmium concentration: $50 \mathrm{mg} \mathrm{l}^{-1}$, adsorbent dose: $8 \mathrm{~g} \mathrm{l}^{-1}, \mathrm{pH} 7$ and contact time: $80 \mathrm{~min}$ )

Based on Fig. 4d, with increasing contact time the efficiency and adsorption capacity increase and consequently the reaction reaches equilibrium after $80 \mathrm{~min}$. The rate of cadmium adsorption was roughly sharp to contact time of 80 . Then, it decreased and the reaction of cadmium adsorption on pumice modified with INPs reached equilibrium. The efficiency was $82.74 \%$ at contact time of 80 min and adsorption capacity was detected $5.97 \mathrm{mg} \mathrm{g}^{-1}$. Quick adsorption at the beginning minutes of contact time is related to that a huge number of active sites on adsorbent surface are available, improving the cadmium diffusion on adsorbent surface (Luo et al., 2013). Also, Luo et al., reported $150 \mathrm{~min}$ as the time of equilibrium of cadmium adsorption via multi-walled carbon nanotubes modified with dioxide magnesium (Luo et al., 2013). Thus, pumice coated with INPs is more economical than multi-walled carbon nanotubes modified with dioxide magnesium.

\subsection{The reaction kinetic and isotherm models}

Optimized points: initial cadmium concentration $50 \mathrm{mg} \mathrm{l}^{-1}$, adsorbent dose $8 \mathrm{gl}^{-1}, \mathrm{pH} 7$ and contact time $80 \mathrm{~min}$ were used for determining reaction kinetic and isotherm models. Fig $5 \mathrm{a}$ and $\mathrm{b}$ shows the results 
of matching the data with kinetics models and table 1 presents the parameters and the correlation coefficients. As can be deduced from the results, the reaction of cadmium adsorption through pumice coated with INPs is better described by the pseudo second-order model. Second order reactions go on with a rate proportionate to the square power of initial matter (Zhu et al. 2010; Mobasherpour et al. 2011). The results obtained accord with those of similar studies in cadmium adsorption by means of multiwalled carbon nanotubes modified with dioxide magnesium as well as zero-valent INPs (Boparai et al., 2011; Luo et al., 2013).

Table 1. The results from the fitness of adsorption kinetics data (initial cadmium concentration $50 \mathrm{mg} \mathrm{l}^{-1}$, adsorbent dose $8 \mathrm{gl}^{-1}, \mathrm{pH} 7$ and contact time $80 \mathrm{~min}$ )

\begin{tabular}{cccccc}
\hline \multicolumn{2}{c}{ Pseudo second-order kinetics model } & \multicolumn{4}{c}{ Pseudo first-order kinetics model } \\
\hline $\mathbf{K}_{\mathbf{2}}$ & $\mathbf{q}_{\mathbf{e}}$ & $\mathbf{R}^{\mathbf{2}}$ & $\mathbf{K}_{\mathbf{1}}$ & $\mathbf{q}_{\mathbf{e}}$ & $\mathbf{R}^{\mathbf{2}}$ \\
\hline 0.06 & 6.19 & 0.98 & 0.06 & 11.21 & 0.91 \\
\hline
\end{tabular}
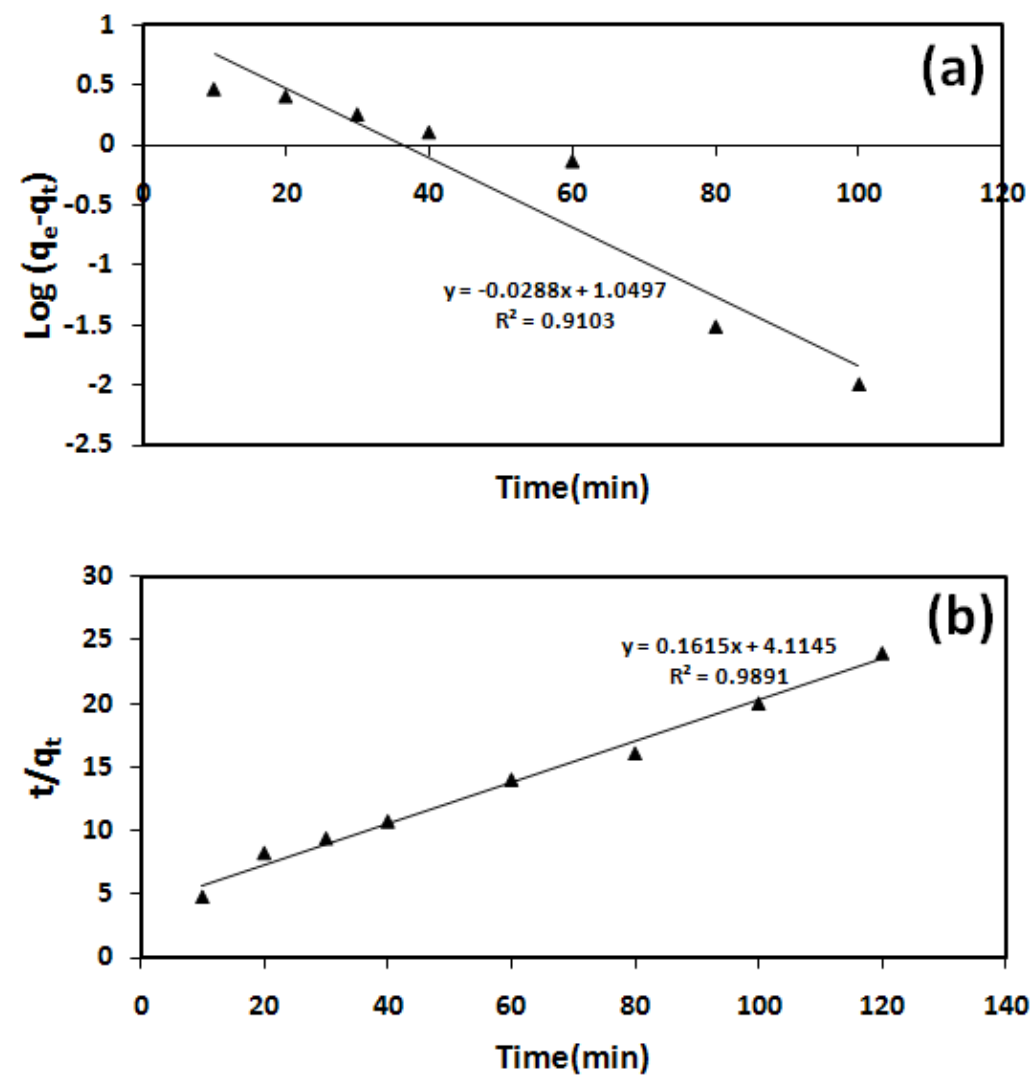

Figure 5. Matching the results from adsorption with kinetics models (a) pseudo first-order and (b) pseudo second-order (initial cadmium concentration: $50 \mathrm{mg} \mathrm{l}^{-1}$, adsorbent dose: $8 \mathrm{~g} \mathrm{l}^{-1}$, contact time: $120 \mathrm{~min}$ )

In order to analyze the results of the adsorption and the isotherms, Langmuir and Freundlich models were investigated and the adsorption diagrams by these models and their coefficients and constants have been given in Fig. $6 a$ and $b$ and table 2, respectively.

Table 2. The results from fitness of adsorption equilibrium data (initial cadmium concentration: 25-125 $\mathrm{mg} \mathrm{l}^{-1}$, adsorbent dose: $8 \mathrm{~g}^{-1}$, contact time: $80 \mathrm{~min}$ ).

\begin{tabular}{ccccccccc}
\hline \multicolumn{8}{c}{ Freundlich } & \multicolumn{7}{c}{ Langmuir } \\
\hline $\mathbf{n}$ & $\mathbf{K}_{\mathbf{f}}$ & $\mathbf{R}^{\mathbf{2}}$ & $\mathbf{\Delta q}(\%)$ & $\mathbf{q}_{\mathbf{m}}$ & $\mathbf{b}$ & $\mathbf{R}_{\mathbf{L}}$ & $\mathbf{R}^{\mathbf{2}}$ & $\mathbf{\Delta q}(\%)$ \\
\hline 1.5 & 0.87 & 0.95 & 4.356 & 17.27 & 0.03 & $0.19-0.54$ & 0.88 & 11.897 \\
\hline
\end{tabular}


The findings showed that adsorption process is followed both Langmuir and Freundlich models and this following is more in the Freundlich model which is indicative of being multilayer adsorption of cadmium ions on pumice coated with iron and heterogeneous surface of the adsorbent (Zhu et al., 2010). The highest amount of cadmium adsorption $\left(q_{\max }\right)$ was $17.27 \mathrm{mg} \mathrm{g}^{-1}$. Moreover, the amount of separation factor or equilibrium parameter $\left(R_{L}\right)$ obtained for the reaction ranged between 0.19 and 0.54 illustrating that cadmium adsorption on pumice coated with INPs is suitable. Heterogeneity factor $(n)$ resulting from Freundlich model is larger than 1 presenting the adsorption process under the experiment conditions has been proper and is of chemical adsorption. Isotherms with higher $n$ are categorized as $L$ isotherms and show that there is a high cohesion between adsorbent and adsorbate and the adsorption is chemical (Boparai et al., 2011).
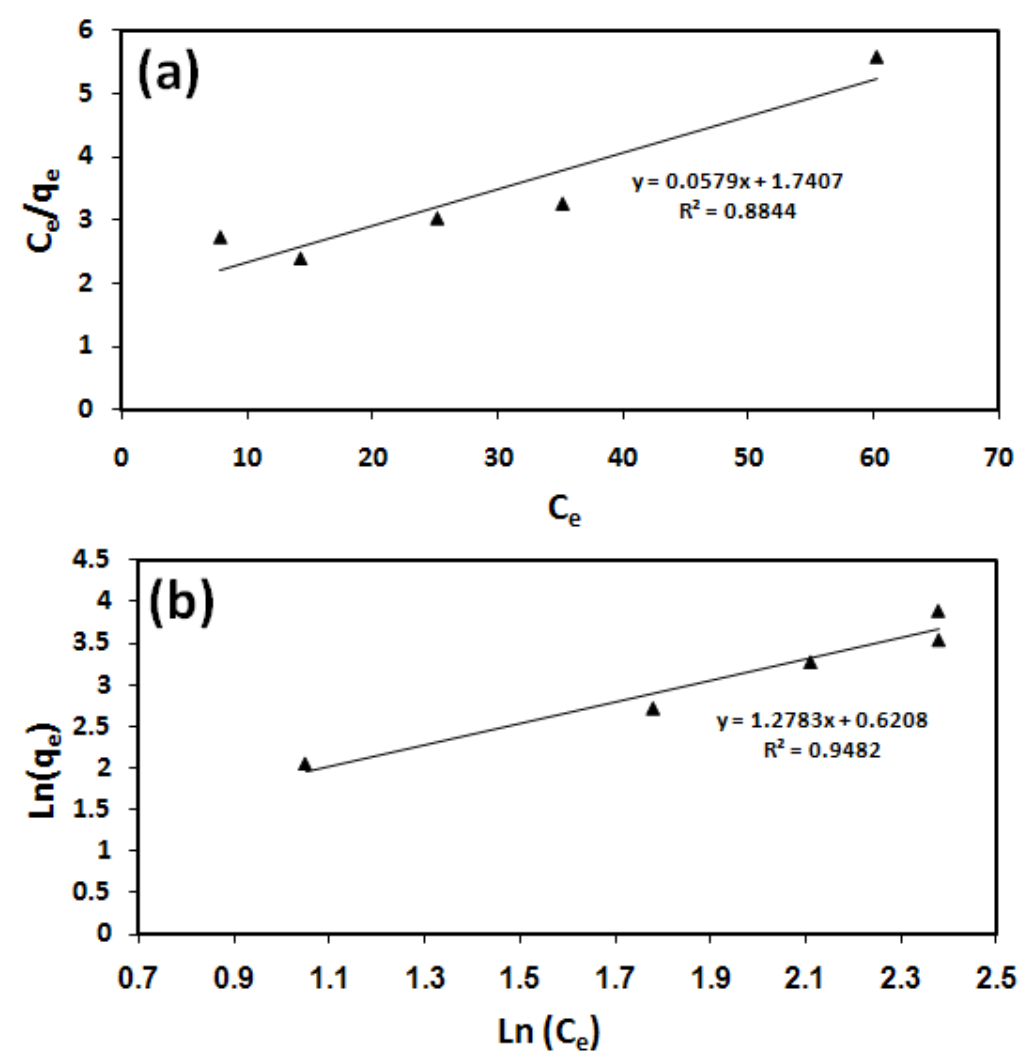

Figure 6. The results of isotherm model investigation (a) Langmuir and (b) Freundlich (initial cadmium concentration: $25-125 \mathrm{mg} \mathrm{l}^{-1}$, adsorbent dose: $8 \mathrm{~g} \mathrm{l}^{-1}$, contact time: $80 \mathrm{~min}$ )

The results of recent studies confirmed that cadmium adsorption via zero-valent iron followed both models, while the processes of cadmium adsoption on zero-valent INPs, nano-hydroxyapatite (n-HA) and orange peel coated with INPs followed the Langmuir isotherm (Gupta and Nayak, 2012; Boparai et al., 2011). Based on table 2, normalized standard deviation $(\Delta q \%)$ were calculated, which were 4.356 and 11.897, respectively, for the isotherms of Freundlich and Langmuir. The less amount of $\Delta q \%$, there will be more fitting among the calculated and experimental data. As can be seen, the isotherm data fit well to the Freundlich model.

\section{Conclusions}

The results of this study showed that pumice stone modified with INPs can remove cadmium well, as the adsorption reaction of cadmium reached equilibrium at a shorter contact time $(80 \mathrm{~min})$ compared to past studies. The highest amount of cadmium removal was seen at $\mathrm{pH}$ ranging between 7 and 9 , which these ranges of $\mathrm{pH}$ do not need to be adjusted in practical applications. The adsorption reaction follows pseudo 
second-order kinetics. Moreover, equilibrium data of adsorption are described by Langmuir and Freundlich models. The highest amount of adsorption capacity was reached at initial cadmium concentration $50 \mathrm{mg} \mathrm{l}^{-1}, \mathrm{pH} 8$, and adsorbent dose $8 \mathrm{gl}^{-1}$. Considering pumice has high porosity and surface area and increases dispersion of INPs and creates more reaction sites for heavy metals, thus, the pumice coated with INPs can be utilized in terms of technical and economical features, as an effective adsorbent for heavy metal removal from aqueous environments.

\section{Acknowledgement}

The authors would like to thank Vice Chancellor for Research and Technology of Hamadan University of Medical Sciences for financial support and Faculty of Health for technical support. It should be said that personal interests do not have any relationship with the results of this manuscript.

\section{Conflicts of Interest}

This study did not have any conflict of interest statement.

\section{References}

Al-Ghamdi A., Altaher H. and Omar W. (2013), Application of date palm trunk fibers as adsorbents for removal of $\mathrm{Cd}^{+2}$ ions from aqueous solutions, J. Water Reuse Desalin., 3(1), 47-54.

Boparai H.K., Joseph M. and O'Carroll D.M. (2011), Kinetics and thermodynamics of cadmium ion removal by adsorption onto nano zerovalent iron particles, J. Hazard. Mater., 186(1), 458-465.

Catalfamo P., Arrigo I., Primerano P. and Corigliano F. (2006), Efficiency of a zeolitized pumice waste as a low-cost heavy metals adsorbent, J. Hazard. Mater., 134(1), 140-143.

Chandy T. and Sharma C.P. (1993), Chitosan matrix for oral sustained delivery of ampicillin, Biomater., 14(12), 939-944.

Coruh S., Gürkan H.E., Kilic E. and Geyikci F. (2014), Prediction of adsorption efficiency for the removal malachite green and acid blue 161 dyes by waste marble dust using ANN, Global NEST Journal, 16(4), 676-689.

Geng B., Jin Z., Li T. and Qi X. (2009), Kinetics of hexavalent chromium removal from water by chitosan-Fe ${ }^{0}$ nanoparticles, Chemosphere, 75(6), 825-830.

Gupta V. and Nayak A. (2012), Cadmium removal and recovery from aqueous solutions by novel adsorbents prepared from orange peel and $\mathrm{Fe}_{2} \mathrm{O}_{3}$ nanoparticles, Chem. Eng. J., 180, 81-90.

Laurent S., Forge D., Port M., Roch A., Robic C., Vander Elst L. and Muller R.N. (2008), Magnetic iron oxide nanoparticles: synthesis, stabilization, vectorization, physicochemical characterizations, and biological applications, Chem. Rev., 108(6), 2064-2110.

Lee S.-M., Laldawngliana C. and Tiwari D. (2012), Iron oxide nano-particles-immobilized-sand material in the treatment of $\mathrm{Cu}$ (II), Cd (II) and Pb (II) contaminated waste waters, Chem. Eng. J., 195, 103-111.

Li Z., Jones H.K., Zhang P. and Bowman R.S. (2007), Chromate transport through columns packed with surfactantmodified zeolite/zero valent iron pellets, Chemosphere, 68(10), 1861-1866.

Liu T., Wang Z.-L. and Sun Y. (2015), Manipulating the morphology of nanoscale zero-valent iron on pumice for removal of heavy metals from wastewater, Chem. Eng. J., 263, 55-61.

Liu T., Wang Z.-L., Yan X. and Zhang B. (2014), Removal of mercury (II) and chromium (VI) from wastewater using a new and effective composite: Pumice-supported nanoscale zero-valent iron, Chem. Eng. J., 245, 34-40.

Liu T., Wang Z.-L., Zhao L. and Yang X. (2012), Enhanced chitosan/Fe ${ }^{0}$-nanoparticles beads for hexavalent chromium removal from wastewater, Chem. Eng. J., 189, 196-202.

Liu T., Zhao L., Sun D. and Tan X. (2010), Entrapment of nanoscale zero-valent iron in chitosan beads for hexavalent chromium removal from wastewater, J. Hazard. Mater., 184(1), 724-730.

Luo C., Wei R., Guo D., Zhang S. and Yan S. (2013), Adsorption behavior of $\mathrm{MnO}_{2}$ functionalized multi-walled carbon nanotubes for the removal of cadmium from aqueous solutions, Chem. Eng. J., 225, 406-415.

Mobasherpour I., Salahi E. and Pazouki M. (2011), Removal of divalent cadmium cations by means of synthetic nano crystallite hydroxyapatite, Desalination, 266(1), 142-148. 
Moraci N. and Calabrò P.S. (2010), Heavy metals removal and hydraulic performance in zero-valent iron/pumice permeable reactive barriers, J. Environ. Manage., 91(11), 2336-2341.

Rahmani A.R., Norozi R., Samadi M.T. and Shirzad Siboni M. (2011), Removal of hexavalent chromium from aqueous solutions by adsorption onto commercial iron powder, kinetic and equilibrium study, Scientific J. Hamadan Univ. Med. Sci., 18(3), 33-39.

Rahmani A.R., Godini K., Nematollahi D. and Azarian G. (2015), Electrochemical oxidation of activated sludge by using direct and indirect anodic oxidation, Desalin. Water Treat., 56(8), 2234-2245.

Regmi P., Moscoso J.L.G., Kumar S., Cao X., Mao J. and Schafran G. (2012), Removal of copper and cadmium from aqueous solution using switchgrass biochar produced via hydrothermal carbonization process, J. Environ. Manage., 109, 61-69.

Pérez-Marín A., Zapata V.M., Ortuno J., Aguilar M., Sáez J. and Lloréns M. (2007), Removal of cadmium from aqueous solutions by adsorption onto orange waste, J. Hazard. Mater., 139(1), 122-131.

Phuengprasop T., Sittiwong J. and Unob F. (2011), Removal of heavy metal ions by iron oxide coated sewage sludge, J. Hazard. Mater., 186(1), 502-507.

Salman T., Temel F.A., Turan N.G. and Ardali Y. (2016), Adsorption of lead (II) ions onto diatomite from aqueous solutions: mechanism, isotherm and kinetic studies, Global NEST Journal, 18(1), 1-10.

Shi L.-N., Zhang X. and Chen Z.-I. (2011), Removal of chromium (VI) from wastewater using bentonite-supported nanoscale zero-valent iron, Water Res., 45(2), 886-892.

Turan N.G., Mesci B. and Ozgonenel O. (2011), The use of artificial neural networks (ANN) for modeling of adsorption of Cu (II) from industrial leachate by pumice, Chem. Eng. J., 171(3), 1091-1097.

Üzüm Ç., Shahwan T., Eroğlu A.E., Hallam K.R., Scott T.B. and Lieberwirth I. (2009), Synthesis and characterization of kaolinite-supported zero-valent iron nanoparticles and their application for the removal of aqueous $\mathrm{Cu}^{2+}$ and $\mathrm{Co}^{2+}$ ions, Appl. Clay Sci., 43(2), 172-181.

Wang X.S., Ren J.J., Lu H.J., Zhu L., Liu F., Zhang Q.Q. and Xie J. (2010), Removal of Ni (II) from Aqueous Solutions by Nanoscale Magnetite, CLEAN-Soil Air Water, 38(12), 1131-1136.

Yavuz M., Gode F., Pehlivan E., Ozmert S. and Sharma Y.C. (2008), An economic removal of Cu 2+ and Cr 3+ on the new adsorbents: pumice and polyacrylonitrile/pumice composite, Chem. Eng. J., 137(3), 453-461.

Zhu H., Jiang R., Xiao L. and Zeng G. (2010), Preparation, characterization, adsorption kinetics and thermodynamics of novel magnetic chitosan enwrapping nanosized $\gamma-\mathrm{Fe}_{2} \mathrm{O}_{3}$ and multi-walled carbon nanotubes with enhanced adsorption properties for methyl orange, Bioresour. Technol., 101(14), 5063-5069. 